\title{
ETIOLOGIA DE MENINGITES BACTERIANAS EM UMA AMOSTRA DA POPULAÇÃO DE SALVADOR - BAHIA
}

\author{
CRISTIANA M. C. NASCIMENTO-CARVALHO*, OTÁVIO A. MORENO-CARVALHO**
}

\begin{abstract}
RESUMO - As meningites bacterianas constituem patologia importante na faixa etária pediátrica. Com o objetivo de conhecer a distribuição da etiologia desta patologia em uma amostra da população de Salvador, Bahia, foram analisados, retrospectivamente, 7000 exames de líquor, realizados entre setembro de 1988 e agosto de 1995, no laboratório de liquorologia da Fundação José Silveira. Foram selecionados 892 (12,7\%) exames realizados em pacientes menores de 16 anos e com suspeita de meningite; entre os 139 casos de meningite bacteriana, $H$. influenzae tipo b foi o agente mais frequente $(26,0 \%)$, ocorrendo em $100 \%$ das vezes em menores de 5 anos. Observou-se tendência na queda do número de casos de meningite por $H$. influenzae tipo b a partir de 1992. Questiona-se se este fato decorre do uso da vacina anti-H. influenzae tipo b nesta amostra da população.
\end{abstract}

PALAVRAS-CHAVE: meningites bacterianas, etiologia, epidemiologia, infância.

\section{Etiology of bacterial meningitis among some children in Salvador - Bahia}

ABSTRACT - Bacterial meningitis remains a very important disease world-wide, mainly during childhood. In order to describe the etiology of bacterial meningitis among some children in Salvador, Bahia - Brazil, we retrospectively reviewed 7000 cerebrospinal fluid exams, performed within the period of September 1988 up to August 1995, at the CSF Laboratory, José Silveira Foundation; 892(12.7\%) exams met the inclusion criteria: patients less than 16 years of age and clinical meningitis diagnosis. Among 139 cases of bacterial meningitis, $H$. influenzae type b (Hib) was the most frequent cause (26.0\%), all of the cases in children under 5 years. We have been questioning whether the declining Hib disease trend since 1992 has been associated with the use of Hib conjugate vaccines among those children.

KEY WORDS: bacterial meningitis, etiology, epidemiology, children.

Em todo o mundo, as meningites bacterianas ainda representam uma patologia muito importante, ocorrendo, predominantemente, na faixa etária pediátrica ${ }^{4,13}$. A incidência anual nos Estados Unidos oscila ao redor de 3 casos por 100000 habitantes, embora esse número varie com idade, raça e $\operatorname{sexo}^{24}$. Os três patógenos mais frequentemente causadores de meningites bacterianas agudas e responsáveis por mais de $80 \%$ dos casos são: Haemophilus influenzae tipo b, Neisseria meningitidis e Streptococcus pneumoniae ${ }^{5,24}$ com taxas de letalidade de 6,0\%, 10,3\% e 26,3\%, respectivamente $^{27}$. Em uma revisão de 4100 casos do Hospital Couto Maia, em Salvador, Bahia, a incidência foi de 45,8 casos por 100000 habitantes, com uma letalidade global de $33 \%{ }^{8}$. Sequelas podem ocorrer, por vezes incapacitantes ${ }^{3,12,20}$. Na década atual, diversos países conseguiram reduzir muito a prevalência de meningites bacterianas na população, implantando o uso rotineiro da vacina conjugada para $H$. influenzae tipo $b^{1,11,21,23,25,26}$.

O objetivo deste estudo foi conhecer a distribuição da etiologia das meningites bacterianas na faixa etária pediátrica, na amostra da população atendida no Laboratório de Liquorologia (LCR) da

*Serviço de Pediatria, Hospital Universitário Professor Edgard Santos, Universidade Federal da Bahia, Brasil: *Professor Assistente; **Laboratório de Liquorologia (LCR) da Fundação José Silveira, Salvador, Bahia, Brasil: Médico Liquorologista. Aceite: 6-outubro-1997.

Dra. Cristiana Nascimento-Carvalho - Rua Aristides Novis 105/1201B - 40210-630 Salvador BA - Brasil. Fax 0712357869. 
Fundação José Silveira, Salvador - Bahia. Este laboratório atende a demanda de exame de líquor em 5 hospitais gerais e em 5 pronto atendimentos pediátricos da rede privada de saúde desta cidade.

\section{MATERIAL E MÉTODOS}

Foram analisadas, retrospectivamente, as fichas de todos os exames de líquor realizados no período de setembro-1988 a agosto-1995, no laboratório de liquorologia (LCR) da Fundação José Silveira, Salvador, Bahia, Brasil. Utilizamos como critério de inclusão idade inferior a 16 anos e suspeita clínica de meningite. Das fichas selecionadas, foram coletadas, para uma planilha de dados, as seguintes informações: número da ficha, data da realização do exame, idade e sexo do paciente, diagnóstico estabelecido após o resultado do exame do líquor; resultado de Gram, cultura, látex-aglutinação e ELISA para bactérias piogênicas, nos casos de meningite bacteriana. Todos os exames foram realizados dentro da rotina para estudo completo do líquor, pela mesma pessoa, no mesmo laboratório. O critério para diagnóstico de meningite bacteriana de etiologia indeterminada foi: celularidade $\geq 200$ células $/ \mathrm{mm}^{3}$, percentual de neutrófilos $\geq 60 \%$, proteína $\geq 100 \mathrm{mg} / \mathrm{dl}$, glicose $\leq 40 \mathrm{mg} / \mathrm{dl}$.

\section{RESULTADOS}

Foram revistas 7000 fichas de exame de líquor, sendo selecionadas 891 (12,7\%) que preencheram o critério de inclusão. Cento e treze exames $(12,7 \%)$ diagnosticaram meningite bacteriana, sendo o diagnóstico etiológico firmado em 78 casos(69,0\%) (Fig 1). O. H. influenzae tipo b foi o agente mais frequente $(23,9 \%)$, seguido da $N$. meningitidis $(22,0 \%)$ e do S. pneumoniae $(7,1 \%)$. Seis pacientes com meningite meningocócica apresentaram-se com meningococcemia $(24,0 \%)$. Entre os bacilos Gram negativos foram identificados: Enterobacter cloacae $(\mathrm{N}=2)$, Pseudomonas aeruginosa $(\mathrm{N}=2)$, Salmonella enteritidis $(\mathrm{N}=1)$, Serratia maecenses $(\mathrm{N}=1)$, Pseudomonas stutzeri $(\mathrm{N}=1)$, não especificados $(\mathrm{N}=5)$. Vinte e seis exames foram realizados para controle de tratamento e/ou evolução de pacientes com meningite bacteriana previamente diagnosticada em outro serviço, sendo a frequência das etiologias discriminada a seguir: $H$. influenzae tipo b (34,6\%), N. meningitidis $(23,1 \%)$, S. pneumoniae $(7,7 \%), S$. aureus $(7,7 \%)$, bacilos Gram negativos $(3,8 \%)$, indeterminada $(23,1 \%)$. (Fig 2). No total dos 139 casos de meningite bacteriana, $H$. influenzae tipo b permaneceu como o agente mais frequente $(26,0 \%)$, seguido de $N$. meningitidis $(22,3 \%)$, S. pneumoniae $(7,2 \%)$, outros agentes $(15,0 \%)$, restando $29,5 \%$ de pacientes com meningite bacteriana de etiologia indeterminada.

Analisamos a distribuição por faixa etária entre os agentes habituais de meningites bacterianas piogênicas e no grupo de etiologia indeterminada (Tabela 1). Um caso de meningite por $\mathrm{N}$. meningitidis, cuja idade era desconhecida, foi incluído na análise por ter sido atendido em Hospital Pediátrico, inferindo tratar-se de paciente na faixa etária estudada. Observamos que 53,0\% das meningites por $H$. influenzae tipo b ocorreram em menores de 1 ano, 100\% em menores de 5 anos,

Tabela 1. Distribuição dos casos de meningite bacteriana por faixa etária e etiologia.

Etiologia

\begin{tabular}{cccccc}
\cline { 2 - 5 } Faixa etária & H. Influenzae tipo b & N. meningitis & S. pneumoniae & Inderteminada & Total \\
\hline 0-3 meses & 0 & $1(3,2 \%)$ & $2(20,0 \%)$ & $4(9,8 \%)$ & $7(5,9 \%)$ \\
3 meses |- 1 ano & $19(53,0 \%)$ & $3(9,7 \%)$ & $23(30,0 \%)$ & $8(19,5 \%)$ & $33(28,0 \%)$ \\
1 ano |- 2 anos & $13(36,0 \%)$ & $2(6,5 \%)$ & 0 & $4(9,8 \%)$ & $19(16,1 \%)$ \\
2 anos |- 5 anos & $4(11,0 \%)$ & $6(19,3 \%)$ & $1(10,0 \%)$ & $3(7,3 \%)$ & $14(11,9 \%)$ \\
$>$ 5 anos & 0 & $18(58,1 \%)$ & $4(40,0 \%)$ & $22(53,6 \%)$ & $44(37,3 \%)$ \\
Desconhecida & 0 & $1(3,2 \%)$ & 0 & 0 & $1(0,8 \%)$ \\
Total & $36(30,5 \%)$ & $31(26,3 \%)$ & $10(8,5 \%)$ & $41(34,7 \%)$ & $118(100 \%)$ \\
\hline
\end{tabular}


Tabela 2. Acurácia dos métodos de diagnóstico etiológico em meningites bacterianas.

\begin{tabular}{cccc}
\hline & \multicolumn{3}{c}{ Método Diagnóstico } \\
\cline { 2 - 4 } Agente etiológico & Gram & Látex e/ou ELISA & Cultura \\
\hline H. Influenzae tipo b & $74,1 \%$ & $77,8 \%$ & $18,5 \%$ \\
N. meningitidis & $62,5 \%$ & $12,5 \%$ & $16,7 \%$ \\
S. pneumoniae & $100 \%$ & $71,4 \%$ & $42,8 \%$ \\
Total & $72,4 \%$ & $50,0 \%$ & $20,7 \%$ \\
\hline
\end{tabular}

sendo o paciente mais jovem com 4 meses de vida; $58,1 \%$ das meningites por N. meningitidis e $53,6 \%$ das meningites de etiologia indeterminada ocorreram em crianças maiores de 5 anos.

Analisamos a acurácia dos métodos de diagnóstico etiológico (Tabela 2). Observamos que os métodos imunológicos tiveram melhor acurácia nos casos de meningite por $H$. influenzae tipo b $(77,8 \%)$ e por $S$. pneumoniae $(71,4 \%)$, enquanto que o Gram foi o método de maior acurácia nos casos de meningite por $N$. meningitidis $(62,5 \%)$ e $S$. pneumoniae (100\%), ficando logo abaixo dos métodos imunológicos nos casos de meningite por $H$. influenzae tipo b $(74,1 \%)$.

Analisamos a ocorrência das meningites bacterianas, por etiologia e por ano (Fig 3), podendo-se observar que as meningites por $H$. influenzae tipo b mostraram tendência para queda a partir de 1992.

\section{DISCUSSÃO}

O perfil etiológico das meningites bacterianas, na amostra da população estudada, está de acordo com os dados da literatura em outras partes do mundo ${ }^{15,17,18,24}$ permanecendo o $H$. influenzae tipo b o agente mais frequente $(26,0 \%)$ (Figs 1 e 2). Em relação à distribuição por idade, observamos que $100 \%$ das meningites por $H$. influenzae tipo b ocorreram em menores de 5 anos, faixa etária em que se preconiza o uso da vacina anti-Haemophilus influenzae tipo $\mathrm{b}^{9,10}$. Houve semelhança na distribuição por idade entre as meningites causadas por $N$. meningitidis e de etiologia indeterminada (Tabela 1). Questionamos se o grupo de meningite bacteriana indeterminada não é composto, na maior parte, por casos de meningite devido à $N$. meningitidis, em que tenham ocorrido fatores que dificultaram o diagnóstico etiológico, por exemplo: punção realizada muito precocemente no curso clínico da doença, ${ }^{16}$ uso prévio de antimicrobianos, ${ }^{19}$ baixa concentração bacteriana e rápida autólise do meningococo após a coleta do líquor ${ }^{14}$. Verificamos, em estudo de tese de mestrado, que o prognóstico nestes 2 grupos também é semelhante, desde que não haja meningococcemia ${ }^{22}$.

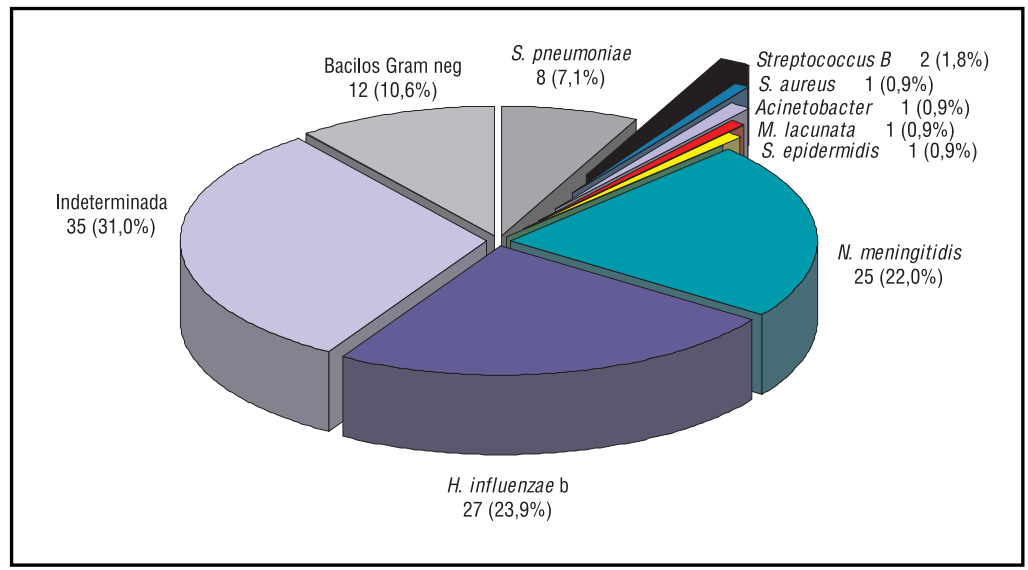

Fig 1. Etiologia de meningites bacterianas em menores de 16 anos. 


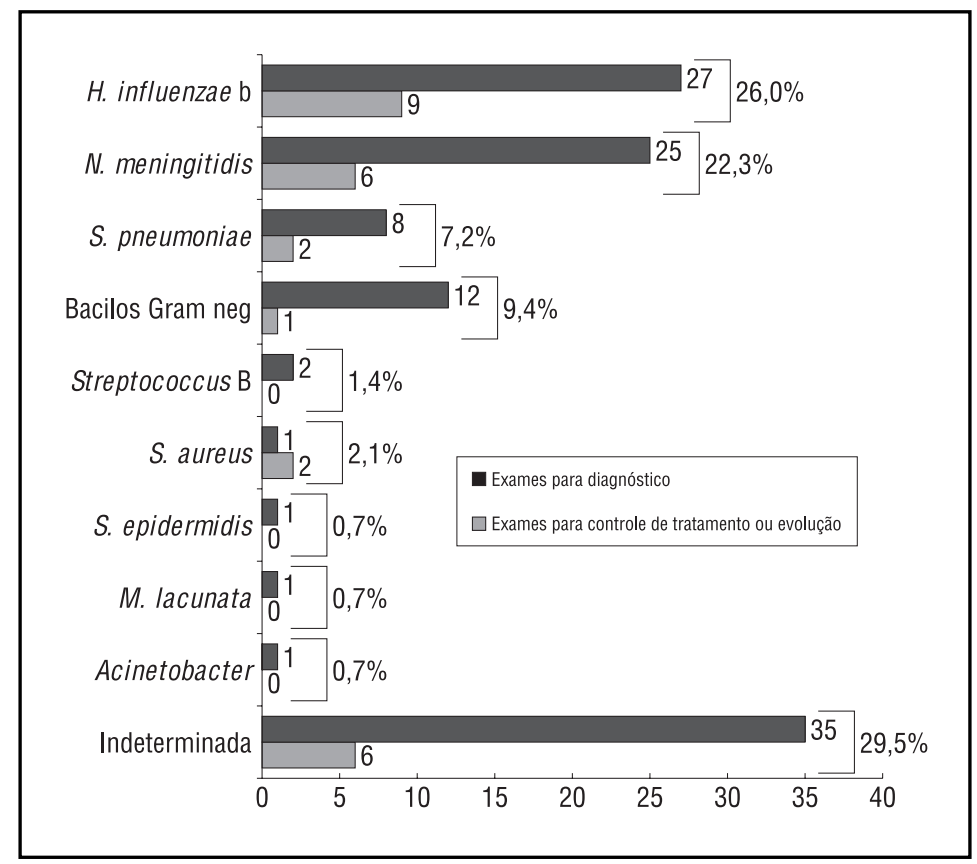

Fig 2. Etiologia de meningites bacterianas em menores de 16 anos.

Ressaltamos a importância da realização do Gram na investigação etiológica dos casos de meningite, principalmente porque sua acurácia foi boa e uniforme nas meningites causadas pelos 3 patógenos habituais (Tabela 2). Chamamos a atenção por ser um método de simples realização, requisitando, principalmente, a execução por profissional experiente ${ }^{6}$.

Chamou nossa atenção a tendência de queda na frequência de meningite por $H$. influenzae tipo b, a partir de 1992, enquanto as meningites causadas pelos demais agentes mostraram tendência para manter o mesmo tipo de curva (Fig 3). Sabemos que, a partir de outubro de 1990, quando a

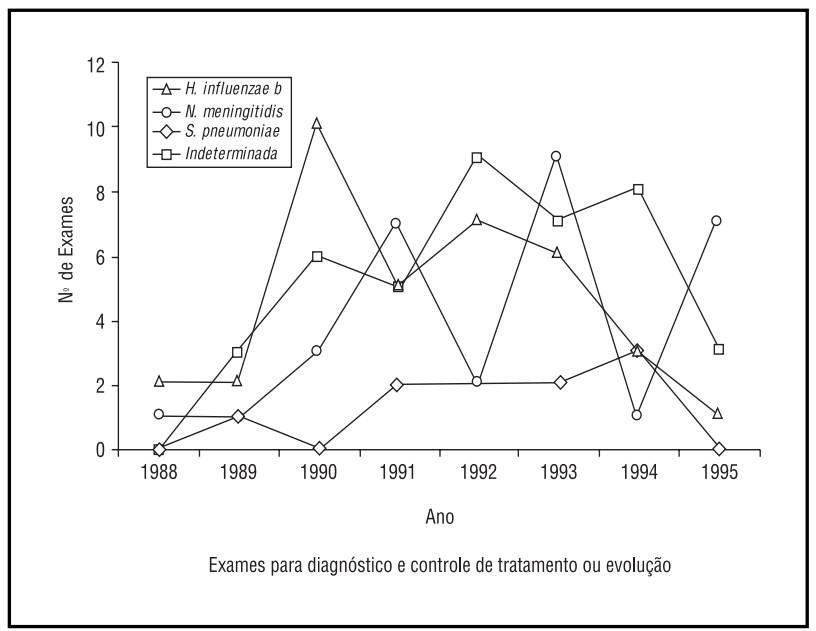

Fig 3. Distribuição das meningites bacterianas por etiologia e ano. vacina conjugada contra $H$. influenzae tipo $\mathrm{b}$ foi licenciada nos Estados Unidos para uso a partir dos 2 meses de vida ${ }^{9,10}$, muitos pediatras em Salvador adotaram tal conduta. Como esta vacina não está disponível na rede pública de saúde da cidade, só as pessoas que podem arcar com o seu custo têm acesso a utilizá-la. Tais pessoas compõem a fatia da população de Salvador atendida no Laboratório de Liquorologia da Fundação José Silveira. Questionamos, pois, se a tendência para o declínio na frequência de meningite por $H$. influenzae tipo b, a partir de 1992, é reflexo do uso 
da vacina conjugada a nível privado. A literatura médica tem registrado o impacto desta vacina, quando usada de rotina em diversas partes do mundo ${ }^{1,2,7,11,21,23,25,26}$.

Concluímos que a distribuição da etiologia das meningites bacterianas em nossa casuística está de acordo com os dados da literatura médica; ressaltamos a importância do Gram na avaliação diagnóstica dos casos suspeitos de meningite e questionamos se o uso da vacina contra $H$. influenzae tipo b, a nível privado, teve influência na queda do número de casos de meningite por Haemophilus influenzae tipo b, na amostra da população estudada.

Agradecimentos - Os autores agradecem à Pasteur Mérieux, Soros e Vacinas, pelo apoio dispensado à realização deste estudo.

\section{REFERÊNCIAS}

1. Adams WG, Deaver KA, Cochi SL, Plikaytis BD, Zell ER, Broome CV, Wenger JD. Decline of childhood Haemophilus influenzae type b(Hib) disease in the Hib vaccine era (see comments). JAMA 1993; 269:221-226.

2. Adegbola RA, Mulholland EK, Falade AG, et al.. Haemophilus influenzae type b disease in the western region of the Gambia: background surveillance for a vaccine efficacy trial. Ann Trop Paediatr 1996:16:103-111.

3. Baraff LJ, Lee SI, Schriger DL. Outcome of bacterial meningitis in children: a meta-analysis. Pediatr Infect Dis J 1993;12:389-394.

4. Barone AA. Meningites bacterinas agudas: etiologia, epidemiologia e patogenia. In Machado LR, Livramento JA, SpinaFrança A, Nóbrega JPS (eds). Neuroinfecção 96. São Paulo: Clínica Neurológica HC/FMUSP, 1996: 141-147.

5. Bell WE. Bacterial meningitis in children: selected aspects. Pediatr Clin North Am 1992;39:651-658.

6. Bonadio WA. Cerebrospinal fluid changes after 48 hours of effective therapy for Haemophilus influenzae type $b$ meningitis. Am J Clin Pathol 1990;94:426.

7. Broadhurst LE, Erickson RL Kelley PW. Decreases in invasive Haemophilus influenzae diseases in US Army children, 1984 through 1991. JAMA 1993;269:227-231.

8. Bryan JP, Silva HR, Tavares A. Etiology and mortality of bacterial meningitis in northeastern Brazil. Rev Infect Dis 1990;12:128-135.

9. Center for Disease Control and Prevention. Food and Drug Administration approval of use of Haemophilus b conjugate vaccine for infants. MMWR 1990;39:698-699.

10. Center for Disease Control and Prevention. Food and Drug Administration approval of use of a Haemophilus b conjugate vaccine for infants. MMWR 1990;39:925-956.

11. Center for Disease Control and Prevention. Progress toward elimination of Haemophilus influenzae type b disease among infants and children: United States, 1987-1995. MMWR 1996;45:901-906.

12. Daund AS, al-Sheyyab M, Batchoun RG, Rawashdeh MO, Nussair MM, Pugh RN. Bacterial meningitis: still a cause of high mortality and severe neurological morbidity in childhood. J Trop Pediatr 1995; 41:308-310.

13. Farhat, CK. Meningites bacterianas purulentas. In Farhat CK, Carvalho ES, Carvalho LHFR, Succi RCM (eds). Infectologia pediátrica. São Paulo: Atheneu, 1993:100-117.

14. Fishman RA. CSF Findings in diseases of the nervous system. In Fishman RA. Cerebrospinal fluid in diseases of the nervous system. 2 Ed. Philadelphia: W. B. Saunders, 1992:256-268.

15. Fortnum HM, Davis AC. Epidemiology of bacterial meningitis. Arch Dis Child 1993;68:763-767.

16. Harrison S, Risser W. Repeat lumbar puncture in the differential diagnosis of meningitis. Pediatr Infect Dis J 1988;7:143-145.

17. Hoen B. Epidémiologie des méningites bactériennes primitives. Rev Prat 1994;44:2148-2151.

18. Ishikawa T, Asano Y, Morishima T, et al.. Epidemiology of bacterial meningitis in children: Aichi Prefecture, Japan, 19841993. Pediatr Neurol 1996,14:244-250.

19. Kaplan S, Smith E, Willis C, Feigin R. Association between preadmission oral antibiotic therapy and cerebrospinal fluid findings and sequelae causaed by Haemophilus influenzae type b meningitis. Pediatr Infect Dis J 1986;5:626-632.

20. Lutsar I, Siirde T, Soopold T. Long term follow-up of Estonian children after bacterial meningitis. Pediatr Infect Dis J 1995; 14:624-625.

21. Murphy TV, White KE, Pastor P, et al.. Declining incidence of Haemophilus influenzae type b disease since introduction of vaccination. JAMA 1993;269:246-248.

22. Nascimento CMPC. Avaliação da antigenemia e antigenúria através dos testes de contra-imunoeletroforese e aglutinação de látex e seu emprego no diagnóstico etiológico e prognóstico das meningites bacterianas na infância. Tese de Mestrado, Faculdade de Medicina da Universidade Federal da Bahia. Salvador, 1994.

23. Peltola H, Kilpi T, Anttila M. Rapid disappearance of Haemophilus influenzae type b meningitis after routine childhood immunisation with conjugate vaccines. Lancet 1992;340:592-594.

24. Schlech WF III, Ward JI, Band JD, Hightower A, Fraser DW, Broome CV. Bacterial meningitis in the United States, 1978 through 1981: the national bacterial meningitis surveillance study. JAMA 1985;253:1749-1754.

25. Shapiro ED. Infections caused by Haemophilus influenzae type b: the beginning of the end? JAMA 1993;269:264-266.

26. Urwin G, Yuan MF, Feldman RA. Prospective study of bacterial meningitis in North East Thames region, 1991-3, during introduction of Haemophilus influenzae vaccine. BMJ 1994;309:1412-1414.

27. Wenger JD, Hightower AW, Facklam RR, Gaventa S, Broome CV. Bacterial meningitis in the United States, 1986: report of a multistate surveillance study. J Infect Dis 1990;162:1316-1323. 